\title{
River, delta and coastal morphological response accounting for biological dynamics
}

\author{
WENDI GOLDSMITH ${ }^{1}$, DARIO BERNARDI ${ }^{2}$ \& LEONARDO SCHIPPA ${ }^{2}$ \\ 1 Bioengineering Group Consulting Firm, Salem, Massachusetts, USA \\ wgoldsmith@bioengineering.com \\ 2 Engineering Department University of Ferrara, Italy
}

\begin{abstract}
Management and construction can increase resilience in the face of climate change, and benefits can be enhanced through integration of biogenic materials including shells and vegetation. Rivers and coastal landforms are dynamic systems that respond to intentional and unintended manipulation of critical factors, often with unforeseen and/or undesirable resulting effects. River management strategies have impacts that include deltas and coastal areas which are increasingly vulnerable to climate change with reference to sea level rise and storm intensity. Whereas conventional assessment and analysis of rivers and coasts has relied on modelling of hydrology, hydraulics and sediment transport, incorporating additional biological factors can offer more comprehensive, beneficial and realistic alternatives. Suitable modelling tools can provide improved decision support. The question has been whether current models can effectively address biological responses with suitable reliability and efficiency. Since morphodynamic evolution exhibits its effects on a large timescale, the choice of mathematical model is not trivial and depends upon the availability of data, as well as the spatial extent, timelines and computation effort desired. The ultimate goal of the work is to set up a conveniently simplified river morphodynamic model, coupled with a biological dynamics plant population model able to predict the long-term evolution of large alluvial river systems managed through bioengineering. This paper presents the first step of the work related to the application of the model accounting for stationary vegetation condition. Sensitivity analysis has been performed on the main hydraulic, sedimentology, and biological parameters. The model has been applied to significant river training in Europe, Asia and North America, and comparative analysis has been used to validate analytical solutions. Data gaps and further areas for investigation are identified.
\end{abstract}

Key words sedimentation; morphodynamic model; bioengineering; biogenic material; climate resilience

\section{BACKGROUND}

Management of rivers and coastal zones has often suffered from decision-making that is poorly coupled to information and accountability related to system dynamics and the direct and indirect effects of human actions. Systems are complex, large and frequently span multiple jurisdictions. Cause and effect relationships commonly are separated by distance and time, making them difficult to recognize and harder to govern in terms of responsibility. Anthropogenic activities such as river damming and sand/gravel mining dramatically affect the sediment balance along rivers producing scouring, bed lowering and coarsening of bed material. Incision of the river bed is one of the most relevant factors responsible for undermining bridges, levees and other infrastructure, and generally exacerbating hydraulic hazards and increasing costs related to ongoing maintenance and disaster losses. Water intakes from river channels or their adjoining aquifers for agricultural and domestic water supply modify the natural seasonal flows and further compound sediment imbalance while affecting riparian and estuarine vegetation. Reduced and altered sediment inputs to deltas and coastal areas contributes to land loss and decreased coastal resilience, even as climate change effects are recognized to cause increased erosive forces and flooding. At the terminus of many rivers, reduced sediment delivery to deltas and other coastal areas leads to accelerated erosion as well as interruptions in land accretion. In both rivers and the coastal landforms that develop where they meet the sea, vegetation plays major roles in reducing erosion, trapping and reinforcing sediment, dissipating hydraulic energy, and accreting land. Vegetation contributes biological materials that become integrated with sediment deposits, often greatly impacting the volume of sediment accumulation in flood plains, deltas and estuaries. Responsible stewardship of river and coastal systems would benefit from improved modelling to account for interactions and dynamic response of biological and geomorphic factors. 


\section{WATERSHED MANAGEMENT FOR CLIMATE RESILIENCE}

Watershed management holds paramount importance in terms of riparian vegetation, regional sediment budgets, and geomorphic evolution of river and coastal landforms. Not only does improved management of rivers correlate with increased resilience of river corridors themselves, but proper stewardship also contributes to coastal resilience. As many regions of the world experience increasingly intense peak rainfalls and channel discharge volumes, damages have become more disruptive and costly, and solutions are being sought. Climate forecasts substantiate that sea level rise, precipitation pattern change, and possibly wind speed and air pressure extremes will likely cause increasing threats including erosion and flooding in riparian and coastal areas. Improved resilience in the face of existing and future impacts and resulting dynamics will depend on optimal management of water, sediment and biological systems in order to foster landform equilibrium processes. Rivers can absorb and recover from high volume flows when riparian vegetation is robust and well developed. River training and bank armouring structures function best when they include vegetation, sometimes combined with rock, concrete and other hard materials. Morphological development of deltas and other coastal landforms relies heavily on more than mineral sediment. Biogenic sediments are significant for coastal land building, including shell and reef material as well as organic matter in marshes and swamps. Yet current modelling tools and conventional practices do not account for vegetation and other biological contributions to morphodynamic processes. Biologically derived material includes roots, shoots, woody debris, peat, humus, shells, bio-cements, and living biomass, all of which are capable of adding stability and volume to landforms. Given that carbon sequestration is one of the benefits of all these biologically derived materials, including when they are embedded into sediment deposits, solutions can jointly address climate change mitigation while improving resilience.

Low lying areas, especially deltas, face high and increasing risks of flooding and physical damage with related chronic and episodic impacts. Sea level rise, land subsidence, and elevated storm intensity pose threats to natural systems, agriculture, infrastructure and urban areas. Measures to address flood and erosion risk have included structures such as jetties, floodwalls and levee systems, with numerous documented examples around the world. However, drawbacks from such measures are now understood to include triggering offsite degradation of physical and ecological systems, as well as requiring costly upkeep and replacement. In recent years beach nourishment has been taken up widely to provide ongoing energy dissipation through beach and dune landforms, even when local sediment budgets do not adequately provide for them. Varied methods have been applied with useful results over differing time spans. In the past decade, The Netherlands has expanded on beach nourishment concepts through assessment of regional and national coastal sediment budgets, including apparent deficits in light of climate change impacts. Other regions have begun to follow suit, calculating sediment inputs, and evaluating sediment dynamics under various future climate change regimes, in order to identify what volumes of sediment would be needed to minimize impacts of storm and flood damage. Notably absent, however, is consideration of biogenic material and the role of vegetation for stabilizing landforms. Hence modelling tools that can address this significant set of factors would be timely and helpful.

\section{SUSTAINABILITY RIVER MANAGEMENT MODEL CONSIDERATIONS}

The principles of integrated watershed management and environmental sustainability are compatible with a river and coastal training approach oriented to bioengineering techniques in order to ensure ecological restoration and long-term balance in the face of climate change. Because vegetation dynamics induce channel geometry modification, and alter sediment deposition and landform development, these responses must be considered to simulate long-term effects. Many benefits of biological processes and biogenic sediment materials can be considered and managed when models adequately account for their behaviour under varied scenarios. Since morphodynamic evolution exhibits its effects on a large timescale the choice of the mathematical model is not trivial and it depends upon the availability of data, the spatial and time extent and the computation effort requested. 
Biomorphodynamic stochastic and deterministic models have been recently developed, but most of these models (Brookes et al. 2000, 2004, Hooke et al. 2005) do not take into account the active role of vegetation and, in turn, the effects of morphological changes on the vegetation growth. Recently, Corenblit et al. (2007) introduced a "fluvial biogeomorphic succession" concept, coupling landform and riparian vegetation evolution in bi-directional modelling.

In fact the dynamic interaction between hydrodynamics and vegetation is not trivial, and it plays a relevant role in terms of landform control factors, because of both the hydrogeomorphic controls on riparian vegetation dynamics and the effects of vegetation on hydrodynamic pattern and sediment transport.

Very often in the deterministic approaches the two aspects are treated separately. Among them Ikeda and Izumi (1990) studied the influence of bank vegetation on the cross-sectional geometry of straight gravel rivers, leading to the following equation for the water depth at the centreline $D_{c}$ :

$$
D_{c}=\frac{0.0306}{\Phi_{j}^{2}} R_{s} m^{0.0933} d_{50} S^{-1}
$$

where $\Phi_{j}$ represents the dimensionless depth averaged fluid velocity depending on the vegetation density, $R_{s}$ is the submerged specific gravity of the sediment, $m$ is a parameter, $d_{50}$ is the sediment representative diameter and $S$ is the bed slope (dimensionless). The presence of bank vegetation decreases the near bank velocity and related shear stress, and increases bank stability binding the sediment with vegetation roots; it results in increasing the angle of repose of the bank material (Jang and Shimizu 2007). Vegetation also affects meandering channel width; on one hand it reduces erosion and increases bank accretion (Beeson and Doyle 1995); on the other hand the presence of vegetation may increase resistance to flow and consequently channel widening because of overbank flowing.

Stochastic models treat the relationship between riparian vegetation population and hydrological variables. Some conceptual model have been developed accounting for probabilistic aspects of hydrological variability such as river discharge annual distribution and the related frequency, duration and intensity of inundation, neglecting geomorphological processes and considering a steady river morphology (see Auble et al. 1994). In the minimalist approach only the most relevant processes are investigated, consequently a number of simplification are introduced for a sack of mathematical manipulation.

On the long-term river evolution scale, anthropogenic activities also play a relevant role. Among them river damming, river training and in-stream sand mining are the most impactful. In effect, reservoirs induce a flow regulation and significant hydrological modification on the riverflow, but also operate as a sediment trap, altering sediment mass balance along the stream; river training, very common for navigation purpose in non-regulated streams, alters the active river width producing bed slope change; whereas in-stream sand exploitation modifies the sediment balance, inducing bed lowering.

Therefore, both these aspects (i.e. vegetation impact and human activities) have to be considered in long-term river modelling because they lead to sediment imbalance and geomorphological evolution which, in turn, reflects on riparian vegetation populations. A conveniently simplified river morphodynamic model, coupled with a biological dynamics plant population model is able to predict the long-term evolution of large alluvial river influenced by bioengineering restoration measures. By manipulating data at selected river reaches, vegetation can be aptly characterized and river response can be differentiated.

Generally speaking we may recognize two counteracting factors: biostabilization and biodestabilization. The first is associated with the stabilization of sediment by physically covering or binding it by roots; in contrast, some species living on the surface, or just below it, destabilize the sediment due to deposit feeding activity, increasing porosity and changing sediment composition.

A possibility is to consider the effect of vegetation in the biomorphodynamic model in terms of critical tractive strength and erosion coefficient (Paarlberg et al. 2005). Notwithstanding, a 
physically-based approach to this issue has to take into consideration several interrelated aspects which may lead to unaffordable computational requirements. Therefore it is preferable, at first, to consider a stationary vegetation condition and apply a hydromorphological model accounting for the most relevant human activity impacting the river system.

\section{A physically-based geomorphological model for a stationary vegetation population}

The choice of a one-dimensional model is suitable to represent correctly the morphological processes without an excessive computational burden, especially accounting for a long-term simulation. The model (Schippa and Pavan 2009) is based on the system of three differential equations stating mass and momentum conservation for the liquid phase plus the Exner equation stating mass conservation for the sediment phase:

$$
\mathbf{U}_{t}+\mathbf{F}(\mathrm{U})_{x}=\mathbf{S}(\mathrm{U})
$$

where:

$$
U=\left[\begin{array}{c}
A \\
Q \\
A_{b}
\end{array}\right] \quad F=\left[\begin{array}{c}
Q \\
\frac{Q^{2}}{A}+g I_{1} \\
\frac{1}{1-p} Q_{s}
\end{array}\right] \quad S=\left[\left.g \frac{d I_{1}}{d x}\right|_{z w=c o n s t} ^{q}-g A S_{f}\right]
$$

In the system of equation (2), $x$ is the longitudinal river coordinate, $t$ is time, $\mathbf{U}$ is the vector of state variables, $\mathbf{F}$ is the vector of fluxes and $\mathbf{S}$ contains source terms. In equation (3), $A$ is the wetted cross-section area, $Q$ is the liquid discharge, $g$ is the gravity acceleration, $I_{l}$ is the static moment of $A$ with respect to the water surface, $S_{f}$ is the friction slope, $A_{b}$ is the sediment volume per unit length of the stream subject to erosion or deposition ("sediment area"), $Q_{s}$ is the solid discharge in volume, $p$ is the bed porosity, $q$ and $q_{s}$ are the liquid and solid lateral inflows (or outflows) per unit length, respectively. The traditional form of the source term in momentum conservation law is slightly changed to avoid the explicit reference to a value for local bottom slope, which in non-prismatic natural rivers with abrupt changes in slope is undesirable (Schippa and Pavan 2008).

Solving equation (2) leads to updating of the value of $A_{b}$ at every time step along the reach. A conversion into a bed elevation variation $\Delta s$ for every point of the cross-sections is needed. We assume that this variation is proportional to bottom shear stress, in turn linearly related to the local water depth $h$ via a constant $k(\Delta s=k h)$. The variation of $A_{b}$ is given by integrating $\Delta s$ along the wetted perimeter $P$ :

$$
\int_{P} \Delta s d p=\Delta A_{b}
$$

Applying the same integral to $k h$ leads to the integral of water depth along the wetted perimeter, which is the wetted area $A$, and consequently equation (5) follows. The local bed elevation change can be calculated directly by $\Delta s=k h$ :

$$
k=\frac{\Delta A_{b}}{A}
$$

A Godunov-type finite volume scheme has been adopted to integrate equation (1), first-order accurate both in space and time. A two-step splitting form of the scheme has been implemented, first solving the homogeneous part of the system and obtaining an intermediate step solution, $\mathrm{U}^{n+1 / 2}$, then integrating the ODEs involving source terms by the Euler method to obtain the solution $\mathrm{U}$ at the time step $n+1$ (Bernardi et al. 2014).

To obtain the fluxes $\mathbf{F}$ in order to solve the homogeneous system in the finite volume framework, the Riemann problem formed at every time step by discontinuities in state variables at cell interfaces has to be solved. The Riemann solvers approximation refers to a modified Goutière et al. (2008) approach; see Bernardi et al. (2014) for details. 
In the following section we present different applications of the model to large sand rivers to illustrate the merit of the approach.

\section{Model application: the case of Red River (Vietnam)}

The Red River (Song Hong) rises in Yunnan province (China) and flows southeast towards Vietnam and the Tonkin Gulf. Its total length is $1140 \mathrm{~km}$ and the total basin area is $157000 \mathrm{~km}^{2}$. The Red River is actually named Thao up to the confluence with the Da and Lo tributaries, located close to Viet Tri. Immediately upstream of the Vietnam capital, Hanoi, a large bifurcation with Duong River partially diverts the flow towards the city of Pha Lai. The lower course ends in a wide delta and is surrounded by many large and populated agricultural districts. Our study area is a $82-\mathrm{km}$ long reach of the Red River, from the gauging station of Son Tay to the village of Phu Minh, located approx. $40 \mathrm{~km}$ downstream of Hanoi (Fig. 1)

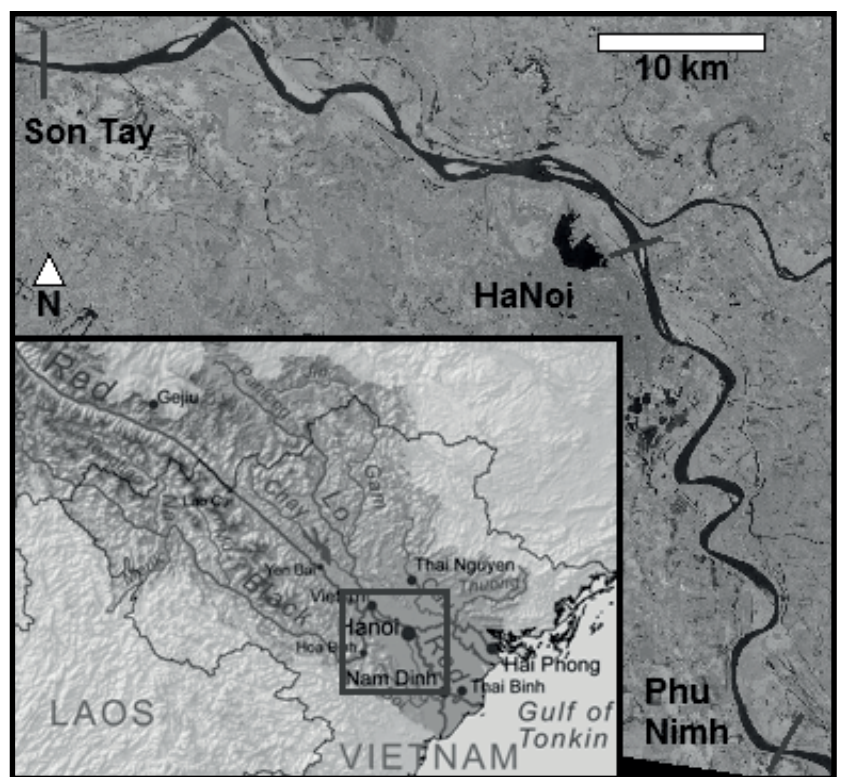

Fig. 1. Lower course of the Red River in Vietnam.

Instream sand mining is deeply affecting river morphology enhancing the bed incision process. Water releases from big reservoirs in the upstream catchments (Thac Ba on Lo River and Hoa Binh on Da River) are planned to maximize the hydroelectricity production, guarantee agricultural water supply and reduce flood risk on the most populated area downstream (i.e. Hanoi). Validation of the model is performed taking as initial conditions the cross-section surveyed in 2000, and running 10-year long simulation runs with the recorded discharge series in Son Tay (2000-2009) as the upstream boundary condition. Bifurcation behaviour (on Duong River) is adjusted during this process, testing different bed lowering trends of the Duong River initial cross-section, to calibrate conveyance ratio and flow distribution (Bernardi et al. 2014). Lowering trends are inferred from recorded minimum water levels in the cross-section of Thuong Cat on Duong River, just downstream of the bifurcation. According to the stationary vegetation hypothesis, bed roughness in the reach is assumed as invariant. The results are compared with recorded time series of discharge at the Duong bifurcation and water level in HaNoi.

As for the influence of anthropogenic activities, the effects of flow regulation by the upstream reservoirs and sand mining are considered by comparing the actual situation with a reference scenario avoiding the presence of the reservoir (in terms of flow regulation) and accounting for different sand mining rate in the modelled period (i.e. 2000-2009) .

Sand mining, as expected, accelerates incision in the first upstream reach and reverses the trend in the following downstream reach. Modelling results suggest that stopping or decreasing 
sand mining would probably start a restoring process. The flow control, conversely, appears to affect the morphological processes much less. The results indicate that the effect of flood control alone on river morphology is very limited in the studied stretch, in comparison to sand mining (Bernardi et al. 2014).

\section{Model application: the case of the Po River (Italy)}

This case study (Fig. 2) is a 112-km long reach of the Po River in Italy, running from Piacenza to Boretto, that includes the run-of-the-river hydroelectricity plant of Isola Serafini (IS). The power station, is served by a $350-\mathrm{m}$ wide dam and has a total capacity of $80 \mathrm{MW}$. The incoming discharge is partially diverted to the hydropower plant channel, which originated as a meander cutoff during the huge 1951 flood and rejoins the Po about $12 \mathrm{~km}$ downstream of the gate, after a large meander. The IS dam has eleven vertical sluice gates, all of the same width. Six of them can also operate as sharp-crested weirs.

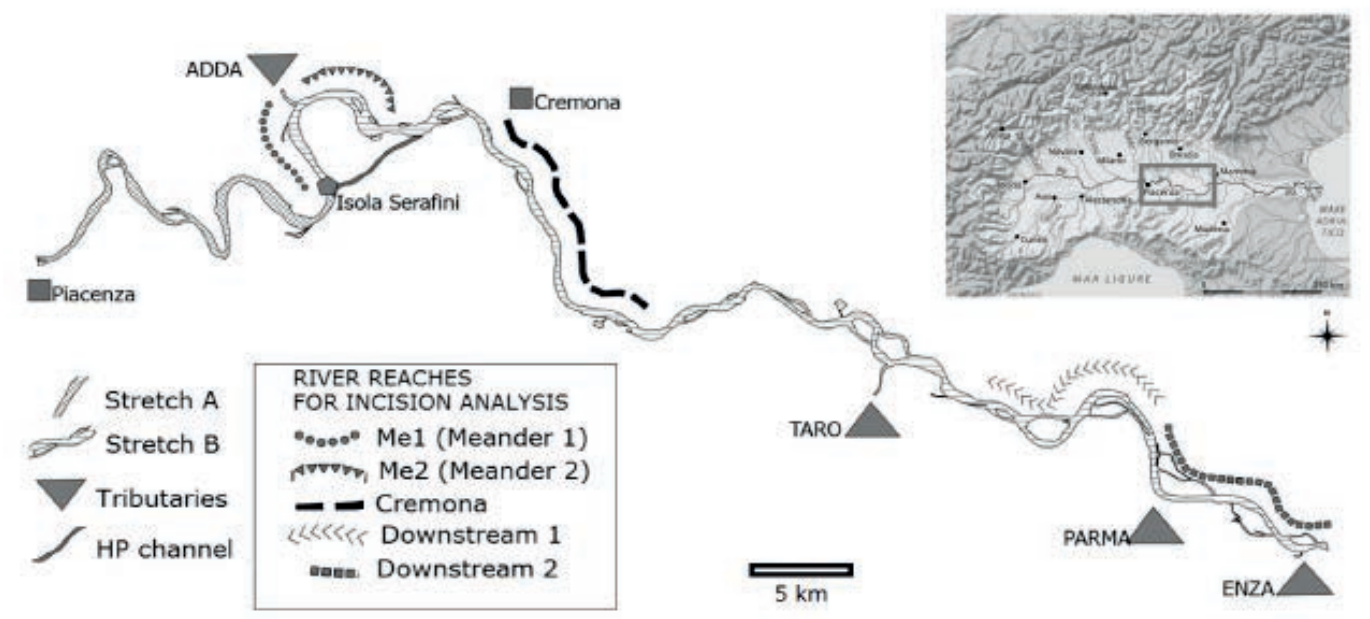

Fig. 2 Middle course of the Po River in Italy.

Due to intense sediment mining as the main cause, the middle course of the Po underwent a strong river bed degradation process in the years from 1950 to 2000, characterized by severe rates until the 1980s. Along with sediment mining, also low water training for navigation purposes and the presence of dams in the upper part of the Po basin affect the overall sediment balance along the middle course.

In this case study the model has been applied to assess the sensitivity of the system to the dam regulation policy and consequently to the upper sediment supply. When the hydropower plant is operating, the original meander is disconnected apart from the MEF (minimum environmental flow) of $100 \mathrm{~m}^{3} / \mathrm{s}$ which is required to flow though the meander. The physical constraints for the variables are given by the MEF in the meander, the minimum and maximum flow through the turbines and the safety limit against flood risk. Starting from the business as usual (BAU) simulation, representing the normal hydropower functioning, many different alternative operating rules have been run (Bernardi et al. 2013) to analyse the sensitivity of the system to the management of the hydropower plant. The results showed the feasibility of the model to represent geomorphodynamic river processes in the presence of a stationary riparian vegetation condition.

\section{Model application: the case of Wax Lake Delta (Louisiana, USA)}

Coastal Louisiana suffers extreme rates of land loss which are predicted to increase due to sea level rise and ongoing land subsidence. This problem is further exacerbated by past and current impacts from levees and fossil fuel extraction that interrupt natural sediment and salinity regimes, hence interfering with the health of vegetation within the coastal area. The Wax Lake Delta has 


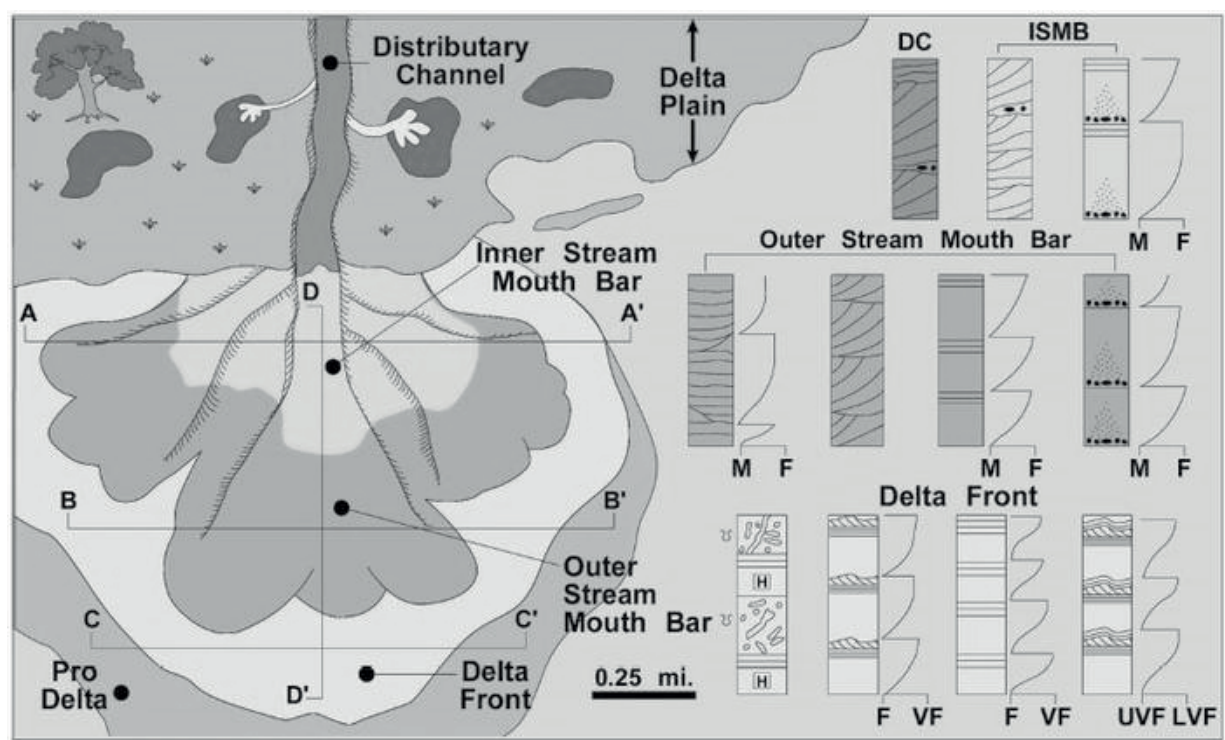

Fig. 3 Wax Lake Delta mineral and organic sediment characteristics; from Wellner et al., 2005.

formed due to anthropogenic manipulation of the Atchafalaya River and its distributary network, resulting in a prograding delta consisting of mineral sediments overlain by organic rich materials (Wellner et al. 2005). As the only significant site (together with the Atchafalaya main channel delta; Rosen and Xu 2013) producing land growth in the region, it has received attention from researchers and policy-makers for over a decade. Modelling has indicated (Kim et al. 2009) that sediment diversions could produce delta formations that would offset roughly half the land loss caused by projected sea level rise and other factors. However, customary sediment analysis has emphasized mineral sediment contributions, without significant attention to processes related to biogenic materials and related ecogeomorphic processes. Potential exists to better define, predict, and manage deposition rates by incorporating combined mineral and organic components. Detailed analysis has established that much organic material is deposited from sources in the upper watershed, contributing to the large-scale sequestration of carbon in Wax Lake Delta sediments (Gordon and Goni 2003). Recent investigations have focused on the relationships between vegetation and sedimentation processes for deltaic island and marsh development (Paola et al. 2011) which suggests the importance of transdisciplinary methods that couple physical, biological, and also social effects.

Efforts are currently underway to enhance the model to account for the deltaic biomorphodynamic processes which are currently of interest in major deltas not only in Louisiana, but around the world. The rich data available from the Wax Lake Delta system is being incorporated to allow calibration of the model to include management practices based on bioengineering and conventional coastal engineering measures. Shellfish reefs and beach nourishment are "inserted" then modelled morphodynamically. Interplay between the river corridor, delta, estuary and dune/ beach landforms and processes are being calibrated through iterative manipulation of potential treatments. It is hoped that biological production can link with other models (organic matter, sediment, shellfish or other populations, etc.). Modelling of coupled physical and biological systems can offer important decision support for major land management actions to provide resilience for coastal areas threatened by land loss.

\section{CONCLUSION AND FURTHER RESEARCH}

The application of a biomorphodynamic model to large rivers is challenging because of the number of parameters and interrelated processes to be considered. As a first step we assessed a stationary riparian vegetation condition and tested a morphodynamic model on large rivers in Asia (Red River) and Europe (Po River), which differ in terms of morphological and hydrological 
condition. The scale of the contribution of organic matter in the formation of the Wax Lake Delta in South Louisiana observed in the period of decades, and known in other major deltas, suggests the importance of refining the model for use in similar settings. Many gaps still exist pertaining to the roles of shellfish (oyster reefs, small organisms, etc.), mangroves, multiple bioengineering measures, and locally adapted plant species and require further development for future modelling of site-scale forcing and response. Larger scale issues that demand further investigation include improved estimates for sediment yield at the watershed scale under various management regimes, resolution of uncertainties dependent upon climate change, and multi-year field calibration to refine model performance.

\section{REFERENCES:}

Auble, G., Friedman, J. and M. Scott, M. (1994) Relating riparian vegetation to present and future streamflow, Ecol. Appl. 4, 544-554.

Baptist, M., et al. (2004) Assessment of the effects of cyclic floodplain rejuvenation on flood levels and biodiversity along the Rhine River. River Res. Applic. 20, 285-297.

Beeson, C. E. and Doyle, P. F. (1995) Comparison of bank erosion at vegetated and non-vegetated channel bends. Water Res. Bull. 31(6), 983-990.

Bernardi D., et al. (2014) Accounting for river morphology in the management of red river (Vietnam): a numerical modeling approach. Proceedings 3rd IAHR Europe Congress, Porto, Portugal (to be published).

Bernardi D., et al. (2013) Integrating mobile bed numerical modeling into reservoir planning operations: the case study of the hydroelectric plant in Isola Serafini (Italy). WIT Transactions on Ecology and The Environment, 178, 63-75.

Brookes, C. J., Hooke, J. M. and Mant, J. (2000) Modelling vegetation interactions with channel flow in river valley of the Mediterranean region. Catena 40, 93-118.

Corenblit D, et al. (2007) Reciprocal interactions and adjustments between fluvial landforms and vegetation dynamics in river corridors: a review of complementary approaches. Earth Science Reviews 84, 56-86.

Gordon, E. and Goni, M. (2003) Sources and distribution of terrigenous organic matter delivered by the Atchafalaya River to sediments in the northern Gulf of Mexico. Geochimica et Cosmochimica Acta, 67(13), 2359-2375.

Goutière L., et al. (2008) One-dimensional model for transient flows involving bed-load sediment transport and changes in flow regimes, Journal of Hydraulic Engineering, 134(6), 726-735.

Hooke, J., Brookes, C. and Mant, J. (2005) A simulation model of the morphological, vegetation and sediment changes in ephemeral streams. Geophys. Res. Lett. 30: LO3402. doi:10.1029/2004GL021966.

Ikeda, S, and Izumi, N. (1990) Width and depth of self-formed straight gravel rivers with bank vegetation. Water Resour. Res., $26(10), 2353-2364$

Jang C.-L. and Shimizu Y. (2007) Vegetation effects on the morphological behavior of alluvial channels. Journal of Hydraulic Research 45(6), 763-772.

Kim, W., et al. (2009) Is it feasible to build new land in the Mississippi River Delta? Eos, Transactions American Geophysical Union 90-42, 373-374.

Paarlberg A.J., et al. (2005) Biological influences on morphology and bed composition of an intertidal flat. Estuarine Coastal and Shelf Science 64, 577-590.

Paola, C., et al. (2011) Natural processes in delta restoration: application to the Mississippi Delta, Annual Review of Marine Science. 3, 67-91.

Rosen, T. and Xu, Y.J. (2013). Recent decadal growth of the Atchafalaya River Delta complex: effects of variable riverine sediment input and vegetation succession. Geomorphology, 10.1016/j.geomorph.2013.04.020.

Schippa, L. and Pavan, S. (2008) Analytical treatment of source terms for complex channel geometry. Journal of hydraulic research 46, 753-763

Schippa, L. and Pavan, S. (2009) Bed evolution numerical model for rapidly varying flow in natural streams. Computers and Geosciences 35, 390-402.

Wellner, R., et al. (2005) Jet-plume depositional bodies - the primary building blocks of Wax Lake Delta. Gulf Coast Association of Geological Societies Transactions 55, 867-909. 